\title{
Culture and Intelligence
}

\author{
Shabnam*
}

\begin{abstract}
:
This paper discusses the relationship between culture and intelligence. This paper mainly describes that intelligence cannot fully or even meaningfully be understood outside its cultural context. Behavior that is considered intelligent in one culture may be considered unintelligent in another culture, and so on. Moreover, people in different cultures have different implicit theories of intelligence, so may not even mean the same thing by the word. The relationships between different aspects of intelligence can vary across cultures, with correlations that are positive in one setting proving to be negative in another. The paper opens with a general discussion of issues regarding the relationship between the two concepts. It then describes the theory of successful intelligence, which also supports interface between culture and intelligence.
\end{abstract}

Keywords: Intelligence, Culture, Theory of Successful Intelligence; Analytical Intelligence, Practical Intelligence

\section{INTRODUCTION}

The field of intelligence is not new it is relatively old. In particular, its practitioners have often assumed that what applies to one culture applies to another. It is important that the much newer field of positive psychology does not repeat these mistakes: that in attempting to understand well-being, it understands intelligence in its multicultural context. Moreover, it is important that the field of positive psychology understands how intelligence, broadly defined, is mostly an attempt to use one's cognitive skills to achieve a state of well-being within one's cultural context. Intelligence is always displayed in a cultural context.

There is the obvious question: What is culture? The term is used here as it was by Berry, Poortinga, Segall, and Dasen (1992). They described six uses of the term: descriptively to characterize a culture, historically to describe the traditions of a group, normatively to express rules and norms of a group, psychologically to emphasize how a group learns and solves problems, structurally to emphasize the organizational elements of a culture, and genetically to describe cultural origins.

The issue of the relationships among culture and intelligence are by no means new. They have been dealt with by Heath (1983); Lave (1988); Luria (1976); Mayer, Tajika, and Stanley (1991); Saxe (1990); and many others who have taken a point of view related to that presented here. Work, discussed here, has enriched the understanding of these relations. Moreover, although

Assistant Professor, Department of Humanities and Social Sciences, National Institute of Technology, (NIT)Kurukshetra (Haryana)

(C) 2014 Shabnam; licensee IJIP. This is an Open Access Research distributed under the terms of the Creative Commons Attribution License (http://creativecommons.org/licenses/by/2.0), which permits unrestricted use, distribution, and reproduction in any Medium, provided the original work is properly cited. 


\section{Culture and Intelligence}

of us believe that culture and intelligence interact (see Sternberg, 2004a), many others do not (see essays in Sternberg \& Grigorenko, 2002b). A substantial majority of intelligence theorists and researchers believe that intelligence is best defined in terms of a universal general ability $(g)$ that is fixed across cultures. It is to be hoped that some of the more contemporary studies described here will change some minds.

The theory motivating much of the work described here is the theory of successful intelligence (Sternberg, 1985, 1997, 1999), according to which "successful intelligence" is defined as what is needed for success in life, according to one's own definition of success, within one's socio cultural context. One acquires and uses these skills and this knowledge by capitalizing on strengths, correcting or compensating for weaknesses, and adapting to, shaping, or selecting environments, through a balance of analytical, creative, and practical abilities. It might seem strange at first to think of one's own definition of success as mattering for successful intelligence. But people develop their intellectual skills in line with where in life they wish to go: Professional tennis player, artists, violinists, and plumbers all need to develop somewhat different (although partially overlapping) sets of intellectual skills to succeed in their respective lines of work. Of course, there are many alternative theories of intelligence as well (e.g., Carroll, 1993; Cattell, 1971; Cattell \& Cattell, 1973;Ceci, 1996; Gardner, 1983, 1999; Guilford, 1967; Gustafsson,1994; Horn \& Cattell, 1966; Jensen, 1998; Spearman, 1927; Thurstone, 1938), many of which are reviewed in Sternberg (1990,2000) and Cianciolo and Sternberg (2004). The field of intelligence has, at times, tended to 'put the cart before the horse', defining the construct conceptually on the basis of how it is operational zed rather than vice versa. This practice has resulted in tests that stress the academic aspect of intelligence, as one might expect, given the origins of modern intelligence testing in the work of Bine t\& Simon (1916) in designing an instrument that would distinguish children who would succeed from those who would fail in school. However, the construct of intelligence needs to serve a broader purpose, accounting for the bases of self-defined success throughout one's life.

The use of societal criteria of success (e.g. school grades, personal income) can obscure the fact that these measures of performance often do not capture people's personal notions of success. Some people choose to concentrate on extracurricular activities such as athletics or music, and payless attention to grades in school; others may choose occupations that are personally meaningful to them but that will never yield the income that they could gain by doing work that is less personally meaningful. In the theory of successful intelligence, the conceptualization of intelligence is individually determined but always occurs within a socio cultural context. Although the processes of intelligence may be common across such contexts, what constitutes success is not. Being a successful member of the clergy of a particular religion may be highly rewarded in one society, but viewed as a worthless pursuit in another culture.

In the theory, one's ability to achieve success depends on the capitalization of one's strengths and correction or compensation for one's weaknesses. Theories of intelligence typically specify some relatively fixed set of abilities, whether this be one general factor and several specific factors (Spearman 1904), seven multiple factors (Thurstone1938), eight multiple intelligences (Gardner 1983, 1999)150 separate intellectual abilities (Guilford 1982). Sucha way of looking at intelligence may be useful in establishing common set of skills to be tested. People achieve success, even within a given occupation, in many different ways. For example, successful teachers and researchers achieve success through many different blending of skills rather than through any single formula that works for all of them. 


\section{Culture and Intelligence}

Definitions of intelligence traditionally have emphasized the role of adaptation to the environment (Intelligence and its Measurement 1921; Sternberg \& Detterman 1986). But intelligence involves not only modifying oneself to suit the environment (adaptation), but also modifying the environment to suit oneself (shaping) and sometimes finding a new environment that is a better match to one's skills, values or desires (selection). Not all people have equal opportunities to adapt to, shape and select environments. In general, people of higher socioeconomic standing tend to have more opportunities and people of lower socio-economic standing have fewer (Sternberg \& Grigorenko 2004).

The economy or political situation of the society can also be factors. Other variables that may affect such opportunities are education (especially literacy), political party, race, religion, and so forth. For example, someone with a college education typically has many more career options than does someone who has dropped out of high school to support a family. Thus, how and how well an individual adapts to, shapes and selects environments must always be viewed in terms of the opportunities available to them. Finally, success is attained through a balance of analytical, creative and practical abilities. Analytical abilities are those primarily measured by traditional ability tests. Success in life requires one not only to analyze one's own ideas as well as those of others, but also to generate ideas and to persuade other people of their value. This necessity occurs in the world of work, for example when a subordinate tries to convince superior of the value of his or her plan; in the world of personal relationships, when a child attempts to convince a parent to do what he or she wants or when as pouse tries to convince the other spouse to do things in his or her preferred way; and in the school, when a student writes an essay arguing for a point of view.

The theory would interpret the studies described earlier as showing the importance of context in understanding human intelligence. For street children, knowing how to do the mathematics needed to run a street business is a matter of survival; knowing how to solve similar or even identical problems in the classroom is not. The children have adapted to the exigencies of their own environments. The processes needed for solving problems may be largely the same in the classroom and the street contexts, but the different contexts elicit different behavior, just as we may behave every differently in school from the way we do at work, or at work from the way we do at home.

\section{CULTURAL STUDIES}

In a series of studies in a variety of cultures, there are evidences about intelligence and how it might apply in diverse contexts. As explained later in this section, they may apply quite differently, depending nowhere they need to be applied.

(a) Children may develop contextually important skills at the expense of academic ones Investigations of intelligence conducted in settings outside the developed world can often yield a picture of intelligence that is quite at variance with the picture one would obtain from studies conducted only in the developed world. In a study in 1996 in Usenge, Kenya, near the town of Kisumu, Sternberg \& Grigorenko were interested in school-aged children's ability to adapt to their indigenous environment. They devised a test of practical intelligence for adaptation to the environment (see Sternberg \& Grigorenko 1997; Sternberg et al. 2001). The test of practical intelligence measured children's informal tacit knowledge for natural herbal medicines that the villagers believe can be used tonight various types of infections. More than $95 \%$ of the children suffer from parasitic illnesses. Children in the villages use their knowledge of these medicines at an average frequency of once a week in medicating themselves and others. Thus, tests of how to use these medicines constitute effective measures of one aspect of practical intelligence as 


\section{Culture and Intelligence}

defined by the villagers, as well as their life circumstances in their environmental contexts. Their well-being hinges upon their being able to self-medicate. Those who cannot suffer to a greater degree the consequences of the illnesses. Middle-class westerners might find it quite a challenge to thrive or even survive in these contexts, or, for that matter, in the contexts of urban ghettos often not distant from their comfortable homes.

The Kenyan children's ability was measured to identify the natural herbal medicines, where they come from, what they are used for and how they are dosed. Based on work that was carried out elsewhere, it was expected that scores on this test would not correlate with scores on conventional tests of intelligence (Sternberg et al. 2000). To test this hypothesis, the 85 children were administered to the 'Raven colored progressive matrices test' (Raven et al.1992), which is a measure of fluid or abstract-reasoning based abilities, as well as the 'Mill Hill vocabulary scale' (Raven et al. 1992), which is a measure of crystallized or formal knowledge-based abilities. In addition, the children were given a comparable test of vocabulary in their own Dholuo language. The Dholuo language is spoken in the home, English is spoken in the schools.

There was no significant correlation between the test of indigenous tacit knowledge and scores on the fluid-ability tests. But, surprisingly, there were statistically significant correlations of the tacit-knowledge tests with the tests of crystallized abilities. The correlations, however, were negative. In other words, the higher the children scored on the test of tacit knowledge, the lower they scored, on average, on the tests of crystallized abilities. Tests of fluid abilities also showed correlations with practical intelligence in the negative direction.

These surprising results can be interpreted in various ways, but based on the ethnographic observations of the anthropologists on the team, it is concluded that a plausible scenario takes into account the expectations of families for their children. Many children drop out of school before graduation, for financial or other reasons. Moreover, many families in the village do not particularly value formal western schooling.

There is no reason why they should, since the children of many families will, for the most part, spend their lives farming or engaged in other occupations that make little or no use of western schooling. Few, if any, will go to universities. These families emphasize teaching their children the indigenous informal knowledge that will lead to successful adaptation to the environments in which they will really live. Children who spend their time learning the indigenous practical knowledge of the community generally do not invest heavily in doing well in school, whereas children who do well in school generally do not invest as heavily in learning the indigenous knowledge: hence the negative correlations. In some cases, they do not learn the indigenous knowledge because no one wants to take them on as apprentices to teach them. They may therefore be perceived as the 'losers' in the village. The Kenya study suggests that the identification of a general factor of human intelligence may tell us more about how abilities interact with patterns of schooling and especially western patterns of schooling, than it does about the structure of human abilities. In western schooling, children typically study a variety of subjects from an early age and thus develop skills in a variety of areas. This kind of schooling prepares children to take a standard test of intelligence.

Such a test typically measures skills in a variety of areas. Intelligence tests often measure skills that children were expected to acquire a few years before taking the intelligence test; but as Rog off $(1990,2003)$ and others have noted, this pattern of schooling is not universal and has not even been common for much of the history of humankind. Throughout history and in many places still, schooling, especially for boys, takes the form of apprenticeships in which children learn a craft from an early age. The children learn what they will need to know to succeed in a trade, but not a lot more. They are not simultaneously engaged in tasks that require the 


\section{Culture and Intelligence}

development of the particular blend of skills measured by conventional intelligence tests. Hence it is less likely that one would observe a general factor in their scores, much as it is discovered in Kenya.

(b) Children may have substantial practical skills that go unrecognized in academic tests

There are related although certainly not identical results in a study of Yupik Eskimo children in southwestern Alaska (Grigorenko et al. 2004a). These children were taken because their teachers thought them, for the most part, to be quite lacking in the basic intelligence needed for success in school. However, many of the children had tremendous practical knowledge that few, if any, of the teachers had, such as how to travel from one village to another in the winter on a dogsled in the absence of landmarks that would have been recognizable to the teachers (or to us). There is the importance of academic and practical intelligence in rural and urban Alaskan communities. A total of 261 high-school children were rated for practical skills by adults or peers in the study: 69 in grade 9, 69 in grade 10, 45 in grade 11 and 37 in grade 12. Out of these children, 145 were females and 116 were males, and they were from seven different communities: six rural and one relatively urban. Academic intelligence was measured with conventional measures of fluid and crystallized intelligence. Practical intelligence was measured with a test of tacit (informally learned) knowledge as acquired in rural Alaskan Yup'ik communities. The urban children generally outperformed the rural children on a measure of crystallized intelligence, but the rural children generally outperformed the urban children on the measure of Yup'ik tacit knowledge. The test of tacit knowledge was superior to the tests of academic intelligence in predicting the practical, and particularly, hunting skills of the rural children (for whom the test was created), but not of the urban ones. Thus, in terms of the skills that mattered most to the children's everyday lives, the test of practical intelligence was distinctly preferable.

c) Practical intellectual skills may be better predictors of health than academic ones

In their study, Grigorenko \& Sternberg (2001) tested 511 Russian school children (ranging in age from 8 to 17 years) as well as 490 mothers and 328 fathers of these children. They used entirely distinct measures of analytical, creative and practical intelligence. Fluid analytical intelligence was measured by two subtests of a test of non-verbal intelligence. The 'test of g: culture fair, level II' (Cattell \& Cattell 1973) is a test of fluid intelligence designed to reduce, as much as possible, the influence of verbal comprehension, culture and educational level, although no test completely eliminates such influences. In the first subtest, 'series', individuals were presented with an incomplete, progressive series of figures.

The participants' task was to select, from among the choices provided, the answer that best continued the series. In the 'matrices' subtest, the task was to complete the matrix presented at the left of each row. The test of crystallized intelligence was adapted from existing traditional tests of analogies and synonyms or antonyms used in Russia. Grigorenko \& Sternberg (2001) used adaptations of Russian rather than American tests because the vocabulary used in Russia differs from that used in the USA. The first part of the test included 20 verbal analogies (internalconsistency reliability, 0.83). An example is 'circle ball 1/4 square? (i) Quadrangular, (ii) figure, (iii) rectangular, (iv) solid, (v) cube'. The second part included 30 pairs of words, and the participants' task was to specify whether the words in the pair were synonyms or antonyms (internal-consistency reliability, 0.74). Examples are 'latent-hidden' and 'systematic-chaotic'. The measure of creative intelligence also comprised two parts. The first part asked the participants to describe the world through the eyes of insects. The second part asked participants to describe who might live and what might happen on a planet called 'Priumliava'. No additional information on the nature of the planet was specified. Each part of the test was scored in three different ways to yield three different scores. The first score was for originality (novelty); the 
second was for the amount of development in the plot (quality); and the third was for creative use of prior knowledge in these relatively novel kinds of task (sophistication).The measure of practical intelligence was self-report and also comprised two parts. The first part was designed as a 20 item, self-report instrument, assessing practical skills in the social domain (e.g. effective and successful communication with other people), in the family domain (e.g. how to fix household items, how to run the family budget) and in the domain of effective resolution of sudden problems (e.g. organizing something that has become chaotic). In this study, only the total practical intelligence self-report scale was used. The second part had four vignettes, based on themes that appeared in popular Russian magazines in the context of discussion of adaptive skills in the current society (Sternberg \& Grigorenko 2004). The four themes were, respectively, how to maintain the value of one's savings, what to do when one makes a purchase and discovers that the item one has purchased is broken, how to locate medical assistance in a time of need, and how to manage a salary bonus one has received for outstanding work. Each vignette was accompanied by five choices and participants had to select the best one. Obviously, there is no one 'right' answer in this type of situation. Hence Sternberg and Grigorenko used the most frequently chosen response as the keyed answer. To the extent that this response was suboptimal, this sub optimality would work against us in subsequent analyses relating scores on this test to other predictor and criterion measures.

Clear-cut analytical, creative and practical factors emerged for the tests. Thus, with a sample of a different nationality (Russian), a different set of tests and a different method of analysis (exploratory rather than confirmatory analysis) supported the theory of successful intelligence. In this same study, the analytical, creative and practical tests that were employed were used to predict mental and physical health among the Russian adults. Mental health was measured by widely used paper-and-pencil tests of depression and anxiety, and physical health was measured by self-report. The best predictor of mental and physical health was the practical intelligence measure (or, because the data are co relational, it may be that health predicts practical intelligence, although the connection here is less clear). Analytical intelligence came second and creative intelligence came third. All three contributed to prediction, however. Thus, it is concluded again that a theory of intelligence encompassing all three elements provides better prediction of success in life than does a theory comprising just the analytical element.

The results in Russia emphasized the importance of studying health-related outcomes as one measure of successful adaptation to the environment. Health-related variables can affect one's ability to achieve one's goals in life, or even to perform well on tests, as it is found in Jamaica.

(d) Physical health may moderate performance on assessments

In interpreting results, whether from developed or developing cultures, it is always important to take into account the physical health of the participants one is testing. In a study carried out in Jamaica (Sternberg et al. 1997), it is found that Jamaican school children who suffered from parasitic illnesses (for the most part, whipworm or Ascaris) performed more poorly on higherlevel cognitive tests (such as of working memory and reasoning) than did children who did not suffer from these illnesses, even after controlling for socio-economic status. Thus, many children were poor achievers not because they lacked abilities, but because they lacked good health. If you are moderately to seriously ill, you probably find it more difficult to concentrate on what you read or what you hear than if you are healthy. Children in developing countries are ill much and even most of the time. They simply cannot devote the same attention and learning resources to schoolwork as do healthy children. Do conventional tests, such as of working memory or of reasoning, measure all of the skills possessed by children in developing countries? Work that is done in Tanzania suggests that they do not. 


\section{Culture and Intelligence}

(e) Dynamic testing may reveal cognitive skills not revealed by static testing

The study conducted in Tanzania (see Sternberg \& Grigorenko 1997, 2002; Sternberg et al. 2002) demonstrates the risks of giving tests, scoring them and interpreting the results as measures of some latent intellectual ability or abilities which was administered to 358 school children between the ages of 11 and 13 years near Bagamoyo, Tanzania, tests including a formboard classification test, a linear syllogisms test and a twenty questions test, which measure the kinds of skills required in conventional tests of intelligence. The scores were obtained and could analyze and evaluate, ranking the children in terms of their supposed general or other abilities. However, the tests were administered dynamically rather than statically (Vygotsky 1978; Brown \& French 1979; Brown \& Ferrara 1985; Lidz1991; Haywood \& Tzuriel 1992; Guthke 1993; Grigorenko \& Sternberg 1998; Sternberg \& Grigorenko 2002).Dynamic testing is like conventional static testing in that individuals are tested and inferences about their abilities are made. But dynamic tests differ in that children are given some kind of feedback to help them to improve their scores.

Vygotsky (1978) suggested that children's ability to profit from guided instruction that they received during a testing session could serve as a measure of the children's zone of proximal development, or the difference between their developed abilities and their latent capacities. In other words, testing and instruction are treated as being of one piece rather than as being distinct processes. This integration makes sense in terms of traditional definitions of intelligence as the ability to learn (Intelligence and its Measurement 1921; Sternberg \& Detterman 1986). What a dynamic test does is directly to measure processes of learning in the context of testing, rather than measuring these processes indirectly as the product of past learning. Such measurement is especially important when not all children have had equal opportunities to learn in the past. In the assessments, children were first given static ability tests. Experimental-group children were then given a brief period of instruction in which they were able to learn skills that would potentially enable them to improve their scores.

Control-group children were not given such instruction. Then they were all tested again. Because the instruction for each test lasted for only ca. 5-10 min, one would not expect dramatic gains. However, on average, the gains in the experimental group were statistically significant. The experimental group also showed significantly greater gains than did the control group. More importantly, scores of the experimental-group children on the pre-test showed only weak although significant correlations with scores on the post-test. These correlations, at about the 0.3 level, suggested that when tests are administered statically to children in developing countries, the results may be rather unstable and easily subject to influences of training. The reason for this could be that the children are not accustomed to taking western-style tests, and so profit quickly even from small amounts of instruction as to what is expected from them. By contrast, the correlations for the control group were at the 0.8 level, as would be expected when one merely administers a pre-test and a post-test without an experimental intervention.

Of course, the more important question is not whether the scores changed or even correlated with each other, but rather how they correlated with other cognitive measures. In other words, which test was a better predictor of transfer to other cognitive performance, the pre-test score or the post-test score? The post-test score were found to be the better predictor in the experimental group.

In the Jamaica study described earlier, failed to find effects of anti-parasitic medication, Albendazole, on cognitive functioning. Might this have been because the testing was static rather than dynamic? Static testing tends to emphasize skills developed in the past. Children who suffer from parasitic illnesses often do not have the same opportunities to profit from instruction that 


\section{Culture and Intelligence}

healthy children have. Dynamic testing emphasizes skills developed at the time of test. Indeed, the skills or knowledge are specifically taught at the time of the test. Would dynamic testing show effects of medication (in this case, praziquantel for schistosomiasis) not shown by static testing? The answer was yes. Over time, treated children showed a distinct advantage over children who received a placebo, and were closer after time had passed to the control (uninfected) group than were the placebo-treated children. In other words, dynamic testing showed both hidden skills and hidden gains not shown on static tests.

(f) New 'intermediate tests' of cognitive skills reveal new aspects of cognitive performance

In cultural research, school related skills are intermediate between abilities and achievement. Traditional tests of cognitive abilities are quite far removed from school performance. Achievement tests are a form of school performance. In Zambia, Grigorenko et al. (2004b) devised such an intermediate test. Children in school and outside it continually need to be able to follow instructions. Often they are not successful in their endeavors because they do not follow instructions as to how to realize these endeavors. Following complex instructions is thus important for the children's success.

The Z-CAI measures working memory, reasoning and comprehension skills in the oral, written and pictorial domains. The Z-CAI was designed to measure children's ability to follow oral, written and pictorial instructions that become increasingly complex; be simple to implement, so that teachers could be easily trained to administer the instrument; be sensitive specifically to any improvement in cognitive functioning that was a result of improved health status; and be psychometrically sound (valid and reliable) in Zambia. Children tested on the Z-CAI were treated for parasitic illnesses outperformed children who were not treated relative to baseline performance.

(g) Intelligence may be different things in different cultures

Intelligence may be conceived in different ways in different cultures (see reviews in Berry 1997; Sternberg \&Kaufman 1998). Yang \& Sternberg (1997a) reviewed Chinese philosophical conceptions of intelligence. The Confucian perspective emphasizes the characteristic of benevolence and of doing what is right. As in the western notion, the intelligent person expends a great deal of effort in learning, enjoys learning and persists in life-long learning with a great deal of enthusiasm. The Taoist tradition, in contrast, emphasizes the importance of humility, freedom from conventional standards of judgment and full knowledge of oneself as well as of external conditions.

The difference between eastern and western conceptions of intelligence may persist even in the present day. Yang \&Sternberg (1997b) studied contemporary Taiwanese Chinese conceptions of intelligence, and found five factors underlying these conceptions: (i) a general cognitive factor, much like the g-factor in conventional western tests; (ii) interpersonal intelligence (i.e. social competence); (iii) intrapersonal intelligence; (iv) intellectual self-assertion: knowing when to show that you are smart; and (v) intellectual self-effacement: knowing when not to show that you are smart. In a related study but with different results, Chen (1994) found three factors underlying Chinese conceptualizations of intelligence: non-verbal reasoning ability, verbal reasoning ability and rote memory. The difference may be a result of different subpopulations of Chinese, differences in methodology or differences in when the studies were done.

The factors uncovered in Taiwan differ substantially from those identified in US citizens' conceptions of intelligence by Sternberg et al. (1981): (i) practical problem solving; (ii) verbal ability; and (iii) social competence; although in both cases, people's implicit theories of intelligence seem to go quite far beyond what conventional psychometric intelligence tests measure. Of course, comparing the Chen (1994) study with the Sternberg et al. (1981) study 
simultaneously varies both language and culture. Studies in Africa in fact provide yet another window on the substantial differences. Ruzgis \& Grigorenko (1994) argued that, in Africa, conceptions of intelligence revolve largely around skills that help to facilitate and maintain harmonious and stable intergroup relations; intergroup relations are probably equally important and at times more important. For example, Serpell $(1974,1996)$ found that Chewa adults in Zambia emphasize social responsibilities, cooperativeness and obedience as important to intelligence; intelligent children are expected to be respectful of adults. Kenyan parents also emphasize responsible participation in family and social life as important aspects of intelligence (Super \& Harkness 1982, 1986, 1993). In Zimbabwe, the word for intelligence, ngwee, actually means to be prudent and cautious, particularly in social relationships. Among the Baoule, service to the family and community and politeness towards, and respect for, elders are seen as key to intelligence (Dasen 1984).

It is difficult to separate linguistic differences from conceptual differences in cross-cultural notions of intelligence. In a study; converging operations were used to achieve some separation. There are different and diverse empirical operations to ascertain notions of intelligence (Sternberg \& Grigorenko 2004). So, in one study that people identify aspects of competence; in another study, that they identify competent people; in a third study, that they characterize the meaning of 'intelligence', and so forth.

The emphasis on the social aspects of intelligence is not limited to African cultures. Notions of intelligence in many Asian cultures also emphasize the social aspect of intelligence more than does the conventional western or intelligence quotient-based notion (Lutz 1985; Poole 1985; White 1985; Azuma \& Kashiwagi 1987).

It should be noted that neither African nor Asian notions emphasize exclusively social notions of intelligence. These conceptions of intelligence focus much more on social skills than do conventional US conceptions of intelligence, while simultaneously recognizing the importance of cognitive aspects of intelligence. In a study of Kenyan conceptions of intelligence (Grigorenko et al. 2001), it was found that there are four distinct terms constituting conceptions of intelligence among rural Kenyans-rieko (knowledge and skills), luoro (respect), winjo (comprehension of how to handle real-life problems) and paro (initiative) - with only the first directly referring to knowledge-based skills (including but not limited to the academic).

It is important to realize, again, that there is no one overall US conception of intelligence. Indeed, Okagaki \& Sternberg (1993) found that different ethnic groups in San Jose, CA, had rather different conceptions of what it means to be intelligent. For example, Latino parents of schoolchildren tended to emphasize the importance of social competence skills in their conceptions of intelligence, whereas Asian parents tended rather heavily to emphasize the importance of cognitive skills. 'White' parents also emphasized cognitive skills more. Teachers, representing the dominant culture, emphasized cognitive skills more than social-competence skills. The rank order of children of various groups' performance (including subgroups within the Latino and Asian groups) could be perfectly predicted by the extent to which their parents shared the teachers' conception of intelligence. In other words, teachers tended to reward those children who were socialized into a view of intelligence that happened to correspond to the teachers' own. However, social aspects of intelligence, broadly defined, may be as important as or even more important than cognitive aspects of intelligence in later life. Some, however, prefer to study intelligence not in its social aspect, but in its cognitive one. 


\section{Culture and Intelligence}

\section{CONCLUSION}

The purpose of this paper was to review position on culture and intelligence and the paper then presented alternative views. The paper included a short description of Sternberg's Triarchic Theory of Intelligence and his conclusions related to measuring intelligence across cultures. When cultural context is taken into account, (i) individuals are better recognized for and are better able to make use of their talents, (ii) schools teach and assess children better, and (iii) society uses rather than wastes the talents of its members. Intelligence can pretend to measure across cultures simply by translating western tests and giving them to individuals in a variety of cultures. But such measurement is only pretense. Individuals in other cultures often do not do well on tests, nor would they do well on theirs. The processes of intelligence are universal, but their manifestations are not. Intelligence can be used to maximize well-being, but it also can be used to destroy it, as Hitler and many other leaders have shown. By understanding cross-cultural meanings of intelligence and of well-being, we can seek to match intelligence to the attainment of well-being, rather than to its destruction.

\section{REFERENCES}

1. Azuma, H. \&Kashiwagi, K. (1987). Descriptions for an intelligent person: a Japanese study. Japanese Psychological Research29, 17-26.

2. Berry, J. W. (1974).Radical cultural relativism and the concept of intelligence. In J. W. Berry \& P. R. Dasen (ed.), Culture and cognition: readings in cross-cultural psychology (pp. 225-229). London: Methuen.

3. Berry, J. W. (1997).Immigration, acculturation and adaptation. Applied Psychology: An International Review, 46, 5-68.

4. Berry, J. W., Poortinga, Y. H., Segall, M. H., \&Dasen, P. R. (1992).Cross-cultural psychology: Research and applications. New York: Cambridge University Press.

5. Binet, A., \& Simon, T. (1916).The development of intelligence in children. Baltimore: Williams \& Wilkins. (Original work published 1905)

6. Brown, A. L. \& Ferrara, R. A. (1985).Diagnosing zones of proximal development. In J. V. Wertsch(ed.), Culture, communication, and cognition: Vygotskian perspectives (pp. 273-305). New York: Cambridge University Press.

7. Brown, A. L. \& French, A. L. (1979). The zone of potential development: implications for intelligence testing in the year2000. In R. J. Sternberg \& D. K. Detterman (ed.), Human intelligence: perspectives on its theory and measurement(pp.217-235). Norwood, NJ: Ablex.

8. Carroll, J. B. (1993). Human cognitive abilities: A survey of factor-analytic studies. New York: Cambridge University Press. 


\section{Culture and Intelligence}

9. Cattell, R. B. (1971). Abilities: Their structure, growth, and action. Boston: Houghton Mifflin.

10. Cattell, R. B. \&Cattell, A. K. (1973).Measuring intelligence with the culture fair tests. Champaign, IL: Institute for Personalityand Ability Testing.

11. Ceci, S. J. (1996). On intelligence (expanded ed.). Cambridge, MA: Harvard University Press.

12. Cianciolo, A. T., \& Sternberg, R. J. (2004).A brief history of intelligence. Malden, MA: Blackwell.

13. Chen, M. J. (1994).Chinese and Australian concepts of intelligence.Psychology and Developing Societies, 6, 101-117.

14. Dasen, P. (1984). The cross-cultural study of intelligence: Piaget and the Baoule. International Journal of Psychology, 19, 407-434.

15. Gardner, H. (1983). Frames of mind: The theory of multiple intelligences. New York: Basic Books.

16. Gardner, H. (1999). Intelligence reframed. New York: Basic Books.

17. Grigorenko, E. L. \& Sternberg, R. J. (1998).Dynamic testing.PsychologicalBulletin, 124, 75-111.

18. Grigorenko, E. L. \& Sternberg, R. J. (2001). Analytical, creative, and practical intelligence as predictors of self-reported adaptive functioning: a case study in Russia. Intelligence, 29, 57-73.

19. Grigorenko, E. L., Geissler, P. W., Prince, R., Okatcha, F., Nokes, C., Kenny, D. A., Bundy, D. A. \& Sternberg, R. J. (2001). The organisation of Luo conceptions of intelligence: a study of implicit theories in a Kenyan village. International Journal of Behavioral Development,25, 367378.

20. Grigorenko, E. L., Meier, E., Lipka, J., Mohatt, G., Yanez, E. \& Sternberg, R. J. (2004a). The relationship between academic and practical intelligence: a case study of the tacit knowledge of Native American Yup'ik people in Alaska. Learning Individual Differences, $14,183-207$

21. Grigorenko, E. L., Jarvin, L., Kaani, B., Kapungulya, P. P., Kwiatkowski, J. \& Sternberg, R. J. (2004b).Effects of interventions against parasitic illnesses on a test of cognitive skills administered in Zambia.(In preparation.)

22. Guilford, J. P. (1982). Cognitive psychology's ambiguities: some suggested remedies. Psychological Review, 89, 48-59. 


\section{Culture and Intelligence}

23. Guilford, J. P. (1967). The nature of intelligence. New York: McGraw-Hill.

24. Gustafsson, J. E. (1994). Hierarchical models of intelligence and educational achievement. In A. Demetriou\& A. Efklides (Eds.), Intelligence, mind andreasoning: Structure and development (pp. 45-73). Amsterdam, the Netherlands: NorthHolland/Elsevier Science.

25. Guthke, J. (1993).Current trends in theories and assessment of intelligence. In J. H. M. Hamers, K. Sijtsma\& A. J. J. M. Ruijssenaars (ed.), Learning potential assessment(pp. 13-20). Amsterdam: Swets\&Zeitlinger.

26. Haywood, H. C., Tzuriel, D. (1992).Interactive assessment. New York: Springer.

27. Heath, S. B. (1983). Ways with words. New York: Cambridge University Press.

28. Horn, J. L., \&Cattell, R. B. (1966).Refinement and test of the theory of fluid and crystallized intelligence.Journal of Educational Psychology, 57, 253-270.

29. Intelligence and its measurement: A symposium (1921). Journal of Educational Psychology, 12, 123-147, 195-216, 271-275.

30. Jensen, A. R. (1998). The f factor. Westport, CT: Praeger/Greenwood.

31. Lave, J. (1988).Cognition in practice. New York: Cambridge University Press.

32. Lidz, C. S. (1991).Practitioner's guide to dynamic assessment. New York: Guilford.

33. Luria, A. R. (1976). Cognitive development: Its cultural and social foundations (M. Lopez-Morillas\& L. Solotaroff, Trans.). Cambridge,MA: Harvard University Press.

34. Lutz, C. 1985 Ethnopsychology compared to what?Explaining behaviour and consciousness among the Ifaluk. In G. M. White \& J. Kirkpatrick (ed.), Person, self, and experience: exploring Pacific ethno psychologies(pp. 35-79). Berkeley, CA: University of California Press.

35. Mayer, R. E., Tajika, H., \& Stanley, C. (1991). Mathematical problem solving in Japan and the United States: A controlled comparison. Journal of Educational Psychology, 83, 69-72.

36. Okagaki, L. \& Sternberg, R. J. (1993). Parental beliefs and children's school performance. Child Development, 64, 36-56.

37. Poole, F. J. P. (1985).Coming into social being: cultural images of infants in BiminKuskusmin folk psychology. In G. M. White \& J. Kirkpatrick (ed.), Person, self, and experience: exploring Pacific ethnopsychologies(pp. 183-244). Berkeley, CA: University of California Press. 


\section{Culture and Intelligence}

38. Raven, J. C., Court, J. H. \& Raven, J. (1992). Manual for Raven's progressive matrices and Mill Hill vocabulary scales. Oxford Psychologists Press.

39. Rogoff, B. (1990).Apprenticeship in thinking: Cognitive development in social context. New York: Oxford University Press.

40. Rogoff, B. (2003).The cultural nature of human development. London: Oxford University Press.

41. Ruzgis, P. M. \&Grigorenko, E. L. (1994).Cultural meaning systems, intelligence and personality.In R. J. Sternberg \& P. Ruzgis (ed.) Personality and intelligence, (pp. 248270). New York: Cambridge University Press.

42. Saxe, G. B. (1990). Culture and cognitive development: Studies in mathematical understanding. Mahwah, NJ: Lawrence Erlbaum.

43. Serpell, R. (1974).Aspects of intelligence in a developing country.African Social Research, 17, 576-596.

44. Serpell, R. (1996). Cultural models of childhood in indigenous socialization and formal schooling in Zambia. In C. P. Hwang \& M. E. Lamb (ed.), Images of childhood (pp. 129142). Mahwah, NJ: Lawrence Erlbaum.

45. Spearman, C. (1927).The abilities of man. London: Macmillan.

46. Spearman, C. (1904). "General intelligence," objectively determined and measured. American Journal of Psychology, 15(2), 201-293.

47. Sternberg, R. J. (1985).Beyond IQ: a triarchic theory of human intelligence. New York: Cambridge University Press.

48. Sternberg, R. J. (1990). Metaphors of mind. New York: Cambridge University Press.

49. Sternberg, R. J. (1997).Successful intelligence. New York: Plume.

50. Sternberg, R. J. (1999). The theory of successful intelligence.Review of General Psychology, 3, 292-316.

51. Sternberg, R. J. (Ed.). (2000). Handbook of intelligence. New York: Cambridge University Press.

52. Sternberg, R. J. (2004). Culture and intelligence.American Psychologist, 59(5), 325-338.

53. Sternberg, R. J. \&Detterman, D. K. (1986). What is intelligence? Norwood, NJ: Plume. 


\section{Culture and Intelligence}

54. Sternberg, R. J., \&Grigorenko, E. L. (2002).Dynamic testing. New York: Cambridge University Press.

55. Sternberg, R. J., \&Grigorenko, E. L. (2004a). Intelligence and culture: how culture shapes what intelligence means, and the implications for a science of wellbeing. Philosophical Transactions Royal Society London B, 359, 1427-1434

56. Sternberg, R. J. \&Grigorenko, E. L. (1997). The cognitive costs of physical and mental ill health: applying the psychology of the developed world to the problems of the developing world. Eye on Psi Chi, 2, 20-27.

57. Sternberg, R. J. \&Grigorenko, E. L. (2002). Just because we 'know' it's true doesn't mean it's really true: a case study in Kenya. Psychological Science Agenda, 15, 8-10.

58. Sternberg, R. J. \& Kaufman, J. C. (1998).Human abilities.Annual Review of Psychology, 49, 479-502.

59. Sternberg, R. J., Conway, B. E., Ketron, J. L. \& Bernstein, M. (1981).People's conceptions of intelligence.Journal of Personality and Social Psychology, 41, 37-55.

60. Sternberg, R. J., Forsythe, G. B., Hedlund, J., Horvath, J., Snook, S., Williams, W. M., Wagner, R. K. \&Grigorenko, E. L. (2000).Practical intelligence in everyday life. New York: Cambridge University Press.

61. Sternberg, R. J., Nokes, K., Geissler, P. W., Prince, R., Okatcha, F., Bundy, D. A. \&Grigorenko, E. L. (2001). The relationship between academic and practical intelligence: a case study in Kenya. Intelligence, 29, 401-418.

62. Sternberg, R. J., Grigorenko, E. L., Ngrosho, D., Tantufuye, E., Mbise, A., Nokes, C., Jukes, M. \& Bundy, D. A. (2002).Assessing intellectual potential in rural Tanzanian school children.Intelligence, 30, 141-162.

63. Super, C. M. \&Harkness, S. (1982). The development of affect in infancy and early childhood. In D. Wagnet\& H. Stevenson (ed.), Cultural Perspectives on Child Development (pp. 1-19). San Francisco, CA: Freeman.

64. Super, C. M. \&Harkness, S. (1986). The developmental niche: a conceptualization at the interface of child and culture. International Journal of Behavioral Development, 9, 545569.

65. Super, C. M. \&Harkness, S. (1993). The developmental niche: a conceptualization at the interface of child and culture. In R. A. Pierce \& M. A. Black (ed.) Life-span development: a diversity reader (pp. 61-77). Dubuque, IA: Kendall/Hunt Publishing Co.

66. Thurstone, L. L. (1938). Primary mental abilities. Chicago: University of Chicago Press. 
67. Vygotsky, L. S. (1978).Mind in society: the development of higher psychological processes. Cambridge, MA: Harvard University Press.

68. White, G. M. (1985).Premises and purposes in a Solomon Islands ethnopsychology. In G. M. White \& J. Kirkpatrick (ed.) Person, self, and experience: exploring Pacific ethnopsychologies (pp. 328-366). Berkeley, CA: University of California Press.

69. Yang, S. \& Sternberg, R. J. (1997a).Conceptions of intelligence in ancient Chinese philosophy.Journal of Theoretical and Philosophical Psychology,17, 101-119.

70. Yang, S. \& Sternberg, R. J. (1997b).Taiwanese Chinese people's conceptions of intelligence.Intelligence, 25, 21-36. 